\title{
Faktor-Faktor Yang Mempengaruhi Tingkat Kemiskinan di Provinsi Jawa Timur
}

\author{
(Factors that Affect The Level of Poverty in East Java Province \\ (Case Studies in 10 Counties with The Highest Poverty Levels))
}

\author{
Dwi Bagus Mei Alfianto, Nanik Istiyani*, Teguh Hadi Priyono \\ Jurusan Ilmu Ekonomi dan Studi Pembangunan, Fakultas Ekonomi dan Bisnis, Universitas Jember (UNEJ) \\ Jln. Kalimantan 37, Jember 68121 \\ E-mail: istiyanife@gmail.com
}

\begin{abstract}
Abstrak
Pembangunan harus dilakukan secara terpadu dan berkesinambungan, salah satunya dengan mengarahkan pembangunan pada daerah-daerah yang memiliki tingkat kesejahteraan yang rendah agar masalah tingkat kemiskinan dapat teratasi. Penelitian ini bertujuan untuk mengetahui besarnya pengaruh jumlah penduduk, Indeks Pembangunan Manusia (IPM) dan Produk Domestik Regional Bruto (PDRB) terhadap tingkat kemiskinan di Provinsi Jawa Timur. Penelitian ini menggunakan data sekunder berupa tingkat kemiskinan, jumlah penduduk, Indeks Pembangunan Manusia (IPM) dan Produk Domestik Regional Bruto (PDRB) pada 10 Kabupaten di Provinsi Jawa Timur yang meliputi Kabupaten Sampang, Kabupaten Bangkalan, Kabupaten Probolinggo, Kabupaten Sumenep, Kabupaten Pamekasan, Kabupaten Tuban, Kabupaten Pacitan, Kabupaten Bojonegoro, Kabupaten Ngawi dan Kabupaten Lamongan yang memiliki tingkat kemiskinan tertinggi di Provinsi Jawa Timur tahun 20102015. Dengan alat analisis yang digunakan adalah regresi data panel. Hasil penelitian ini menunjukkan bahwa dengan alat analisis data panel jumlah penduduk dan Indeks Pembangunan Manusia (IPM) memiliki pengaruh negatif dan signifikan terhadap tingkat kemiskinan di Provinsi Jawa Timur tahun 2010 - 2015, sedangkan Produk Domestik Regional Bruto (PDRB) memiliki pengaruh positif dan signifikan terhadap tingkat kemiskinan di Provinsi Jawa Timur tahun 2010 - 2015.
\end{abstract}

Kata kunci: Indeks Pembangunan Manusia (IPM), Jumlah Penduduk, Produk Domestik Regional Bruto (PDRB), Tingkat Kemiskinan.

\begin{abstract}
Development must be done in an integrated and sustainable, one of them with direct development on areas that have a low level of well-being so that the problem of poverty level can be resolved. This research aims to know the magnitude of the influence of population, human development index (HDI) and gross Regional domestic product (GDP) against the level of poverty in East Java province. This study uses secondary data in the form of poverty levels, population, human development index (HDI) and gross Regional domestic product (GDP) in 10 regencies in East Java province which includes the Districts of Sampang, Bangkalan Regency Regency Probolinggo Regency, Sumenep, Pamekasan Regency of Tuban, Bojonegoro, district of Pacitan Regency, the districts of Wonogiri and Lamongan which has the highest rate of poverty in East Java province year 2010-2015. With the analysis tools used is regression of the data panel. The results of this research show that the panel data analysis tools with the population and human development index (HDI) has a negative influence and significantly to the level of poverty in East Java province year 2010 - 2015, while Domestic Products (GDP) gross regional influence positively and significantly to the level of poverty in East Java province year 2010 - 2015.
\end{abstract}

Keywords: Human Development Index (HDI), Population, Gross Regional Domestic Product (GDP), The Level of Poverty.

\section{Pendahuluan}

Pembangunan ekonomi merupakan suatu proses yang menyebabkan kenaikan pendapatan riil per kapita penduduk suatu negara dalam jangka panjang yang disertai oleh perbaikan sistem kelembagaan (Arsyad, 1999:11). Pembangunan harus dilakukan secara terpadu dan berkesinambungan agar sesuai prioritas dan kebutuhan masing-masing daerah dengan akar dan sasaran pembangunan yang telah ditetapkan melalui pembangunan jangka panjang dan jangka pendek. Salah satunya dengan mengarahkan pembangunan pada daerah-daerah yang memiliki tingkat kesejahteraan yang rendah. Oleh karena itu salah satu indikator keberhasilan pembangunan nasional adalah laju penurunan jumlah penduduk miskin (Simatupang dan Saktyanu, 2003).
Kemiskinan menjadi perhatian secara global. Secara global muncul konsep Pembangunan Millenium (Millenium Development Goals, MDGs). Sasaran utama MDGs adalah penghapusan kemiskinan ekstrim (exteme poverty) dan kelaparan pada tahun 2015. Beberapa negara masih menghadapi masalah kemiskinan yang cukup tinggi termasuk Indonesia. Sekalipun sudah merupakan komitmen global, upaya penanggulangan kemiskinan bukan merupakan hal sederhana, karena kemiskinan bersifat kompleks. Menurut para ahli ekonomi kemiskinan di Indonesia bersifat multidimensonial. Kemiskinan di Indonesia masih terbilang tinggi karena mayoritas penduduknya di sektor pertanian dan banyak dalam kategori penduduk miskin. Menurut para ahli ekonomi kemiskinan di Indonesia bersifat multidimensonial. Kemiskinan yang bersifat multidimensional dapat dilihat dari berbagai aspek diantaranya aspek primer dan aspek sekunder.

* Corresponding author 
Aspek primer berupa miskin aset, organisasi sosial politik, dan pengetahuan serta keterampilan yang rendah. Aspek sekunder berupa miskin akan jaringan sosial, sumber keuangan dan informasi. Oleh karena itu upaya pengentasan kemiskinan harus dilakukan secara komprehensif, mencakup berbagai aspek kehidupan masyarakat, dan dilaksanakan secara terpadu (M. Nasir, dkk 2008).

Kemiskinan Ragnar Nurkse atau dikenal sebagai teori lingkaran setan kemiskinan (vicious circle of poverty) adalah suatu lingkaran yang merupakan rangkaian yang saling mempengaruhi satu dengan yang lainnya, sehingga menyebabkan suatu keadaan dimana negara akan tetap mengalami kemiskinan dan mengalami kesulitan dalam mencapai pembangunan yang lebih baik kedepannya (Nurdiansyah, 2016). Robert Chambers (1987) mengatakan bahwa kemiskinan merupakan suatu intergrated concept dan inti dari masalah kemiskinan terletak pada apa yang disebut deprivation trap atau perangkap kemiskinan. Hal ini dinilai sesuai kenyataan dan secara konseptual jelas. Secara rinci deprivation trap terdiri dari lima unsur, yaitu : kemiskinan itu sendiri (poverty), kelemahan fisik (physical weakness), keterasingan atau kadar isolasi (isolation), kerentanan (vulnerability), dan ketidakberdayaan (powerlessness). Kelima unsur ini saling berkaitan antara satu dengan lain, sehingga perangkap kemiskinan ini benar-benar terjadi, yang bisa menjerat keluarga miskin.

Pada umumnya terdapat dua indikator untuk mengukur tingkat kemiskinan di suatu wilayah, yaitu kemiskinan absolut dan kemiskinan relatif. Kemiskinan absolut diukur dengan mengacu pada garis kemiskinan, sedangkan konsep kemiskinan yang pengukurannya tidak didasarkan pada garis kemiskinan disebut kemiskinan relatif (Tambunan, 2003). Bank Dunia mengukur garis kemiskinan berdasarkan pada pendapatan per kapita. Penduduk yang memiliki pendapatan kurang dari US\$ 2 per hari masuk dalam kategori keluarga miskin. Selain itu ada indikator lain yang dikemukakan oleh komite penanggulangan kemiskinan yang jauh lebih spesifik dalam melihat kondisi kemiskinan yang dialami oleh masyarakat.

Tingkat kemiskinan di pulau Jawa berbeda di setiap provinsinya. Salah satunya di Provinsi Jawa Timur, perkembangan kemiskinan dalam kurun waktu 2010-2015, secara jumlah dan persentase mengalami penurunan. Dimana pada tahun 2010 jumlah penduduk miskin sebesar 5529,30 ribu jiwa dan persentase penduduk miskin sebesar 14,87 persen, kemudian dari tahun ke tahun menurun menjadi 4893,01 ribu jiwa pada tahun 2013 dengan persentase penduduk miskin sebesar 12,73 persen. Pada tahun 2014 jumlah penduduk miskin 4748,40 ribu jiwa dengan persentase penduduk miskin 12,28 persen. Pada tahun 2015 jumlah penduduk miskin sebesar 4775,97 ribu jiwa dan persentase penduduk miskin 12,28 persen. Jawa Timur dikenal sebagai pusat Kawasan Timur Indonesia dan memiliki signifikasi perekonomian yang cukup tinggi, yakni berkontribusi 14,85\% terhadap Produk Domestik Bruto nasional, namun hal itu tidak menghindarkan Provinsi Jawa Timur dari masalah kemiskinan yang tinggi.

Meskipun dari tahun ke tahun tingkat kemiskinan mengalami penurunan, namun masih terjadi tingkat kemiskinan yang tidak merata di Jawa Timur yang diakibatkan tidak meratanya pembangunan di setiap daerah. Tingkat kemiskinan di Jawa
Timur merupakan tingkat kemiskinan agregat dari 29 kabupaten dan 9 kota di Jawa Timur, sebagian besar tingkat kemiskinan masih tinggi di daerah-daerah tertentu. Untuk itu perlu dicari faktor-faktor yang dapat mempengaruhi tingkat kemiskinan di kabupaten/kota yang masih memiliki tingkat kemiskinan yang tinggi, sehingga dapat digunakan sebagai acuan bagi kabupaten/kota dalam usaha mengatasi kemiskinan.

Pemerintah Provinsi Jawa Timur sudah melaksanakan berbagai program kebijakan untuk menekan tingkat kemiskinan. Ada dua cara yang dilakukan pemerintah yaitu mengurangi beban biaya bagi rumah tangga sangat miskin dan meningkatkan pendapatan rumah tangga miskin serta hampir miskin. Meski sudah dilakukan usaha demikian, namun masih ada kemiskinan yang cukup tinggi terjadi. Oleh karena itu diperlukan suatu strategi penanggulangan kemiskinan yang terpadu, terintregasi sehingga mampu mengurangi masalah kemiskinan.

Fenomena tingkat kemiskinan dalam penelitian ini yaitu mengenai tingkat kemiskinan pada 10 kabupaten di Provinsi Jawa Timur yang memiliki tingkat kemiskinan tertinggi. Sehingga penulis mengambil judul "Faktor-faktor yang mempengaruhi tingkat kemiskinan di Provinsi Jawa Timur", dengan pokok permasalahan seberapa besar pengaruh jumlah penduduk terhadap tingkat kemiskinan di Provinsi Jawa Timur, seberapa besar pengaruh IPM terhadap tingkat kemiskinan di Provinsi Jawa Timur, dan seberapa besar pengaruh PDRB terhadap tingkat kemiskinan di Provinsi Jawa Timur. Adapun tujuan penelitian ini untuk mengetahui besarnya pengaruh jumlah penduduk, IPM dan PDRB terhadap tingkat kemiskinan, terutama di 10 kabupaten Provinsi Jawa Timur yang memiliki persentase penduduk miskin tertinggi.

\section{Metode}

\section{Rancangan atau Desain Penelitian}

Penelitian ini menggunakan pendekatan kuantitatif, seperti yang dikemukakan Stokes (2006:21) penelitian kuantitatif merupakan metode yang didasarkan pada informasi numeric atau kuantitas dan dapat diasosiasikan dengan analisis statistika. Jenis explanatory research, Herjanto (2007:96) menyatakan bahwa penelitian explanatory merupakan penelitian yang diasumsikan adanya hubungan antara variabel bebas (independen) dengan vaariabel terikat (dependen) yang dipengaruhinya.

\section{Jenis dan Sumber Data}

Jenis data yang dipergunakan dalam penelitian ini adalah data sekunder. Jenis data yang digunakan adalah data kurun waktu (time series) dari tahun 2010-2015 dan cross section sebanyak 10 Kabupaten di Provinsi Jawa Timur. Sumber data penelitian ini diperoleh dari Badan Pusat Statistik (BPS) Provinsi Jawa Timur dan berdasarkan penelitian terdahulu.

\section{Unit Analisis}

Unit analisis dalam penelitian ini yaitu Badan Pusat Statistika (BPS) Provinsi Jawa Timur dengan 10 Kabupaten yang memiliki tingkat kemiskinan tertinggi di Provinsi Jawa Timur.

\section{Metode Analisis Data}




\section{Analisis Regresi Data Panel}

Ekananda (2016:35), menyatakan di dalam teori ekonometri, proses penyatuan data antar waktu (time series) dan data antar individu (cross section) disebut dengan pooling. Sedangkan data yang dihasilkan disebut dengan pooled data atau panel data atau longitudinal data.

Dalam model data panel persamaan model dengan menggunakan data cross section dapat ditulis sebagai berikut :

$Y_{i}=\alpha+\beta_{1} X_{i}+\epsilon_{i} ; i=1,2, \ldots, N$

dimana $\mathrm{N}$ adalah banyaknya data cross-section.

Sedangkan model data panel dengan persamaan model data time-series adalah :

$\mathrm{Y}_{\mathrm{t}}=\alpha+\beta_{1} \mathrm{X}_{\mathrm{t}}+; \epsilon_{\mathrm{t}} \mathrm{t}=1,2, \ldots, \mathrm{T}$

dimana $\mathrm{T}$ adalah banyaknya data time-series.

Data panel merupakan gabungan dari data time series dan cross section, maka model dapat ditulis dengan :

$\mathrm{Yit}=\alpha+\beta 1 \mathrm{Xit}+\epsilon_{\mathrm{it}}$

$\mathrm{t}=1,2, \ldots, \mathrm{T} ;$ dan $\mathrm{i}=1,2, \ldots \mathrm{N}$

Keterangan :

$\mathrm{T}$ = Banyaknya waktu

$\mathrm{N}=$ Banyaknya observasi

$\mathrm{N}$ x T= Banyaknya data panel

Adapun fungsi model ekonomi dari variabel-variabel diatas, sebagai berikut:

Tikem $=\mathrm{f}(\mathrm{JP}, \mathrm{IPM}, \mathrm{PDRB})$

Fungsi diatas kemudian dapat ditransformasikan ke dalam model ekonometri sehingga ditulis :

Tikem $=\alpha+\beta_{1} \mathrm{JP}_{\text {it }}+\beta_{2 \mathrm{I}} \mathrm{IPM}_{\text {it }}+\beta_{3} \mathrm{PDRB}_{\text {it }}+\epsilon_{\text {it }}$

dimana :

$$
\begin{array}{ll}
\text { Tikem } & =\text { Tingkat Kemiskinan (\%) } \\
\mathrm{JP} & =\text { Jumlah Penduduk (jiwa) } \\
\mathrm{IPM} & =\text { Indeks Pembangunan Manusia (\%) } \\
\text { PDRB } & =\text { Produk Domestik Regional Bruto (Milyar) } \\
\alpha & =\text { Intersep } \\
\beta \text { it } & =\text { Koefisien variabel } \\
\epsilon & =\text { Error term } \\
\mathrm{i} & =1,2, \ldots, \mathrm{N} \text { (banyaknya sampel/observasi) } \\
\mathrm{t} & =1,2, \ldots, \mathrm{T} \text { (banyaknya waktu) }
\end{array}
$$

Berkaitan dengan penggunaan panel data dalam penelitian ini, maka digunakan tiga teknik analisis, yaitu (Ekananda, 2015;405) :

\section{A.Metode Pooled Least Square (PLS) atau Common Effect}

Model pooled juga sering disebut sebagai model common atau homogenity. PLS adalah struktur model estimasi paling sederhana yang mengkombinasikan antara data time series dan cross section. Di mana estimator akan menghasilkan intersep $\alpha$ dan slope $\beta$ sama untuk setiap individu $\left(\alpha_{1}=\alpha_{2}=\alpha_{3}=\ldots=\alpha_{\mathrm{i}}\right.$ dan $\left.\beta_{\mathrm{k} 1}=\beta_{\mathrm{k} 2}=\beta_{\mathrm{k} 3}=\ldots=\beta_{\mathrm{ki}}\right)$. Dimana $\mathrm{k}$ adalah jenis variabel dan $\mathrm{i}$ adalah observasi ke-i. Persamaan yang digunakan adalah:

Tikem $_{i, t}=\alpha+\beta_{1} \mathrm{JP}_{\mathrm{i}, \mathrm{t}}+\beta_{2} \mathrm{IPM}_{\mathrm{i}, \mathrm{t}}+\beta_{3}$ PDRB $_{\mathrm{i}, \mathrm{t}}+\epsilon_{\mathrm{i}, \mathrm{t}} \backslash$

Struktur model ini mengasumsikan tidak adanya perbedaan karakteristik tingkat kemiskinan (Tikem) di Provinsi Jawa Timur selama waktu observasi.

\section{B. Metode Fix Effect Model (FEM)}

FEM merupakan model yang memperhatikan adanya keberagaman (heterogenitas) dari variabel independen menurut individu. Keberagaman individu diketahui melalui intersep $\alpha$ yang berbeda untuk setiap individu. Dampak dari setiap variabel independen dipertahankan sama untuk setiap individu sepanjang waktu observasi $\left(\alpha_{1} \neq \alpha_{2} \neq \alpha_{3} \neq \ldots \neq \alpha_{i}\right.$ dan $\beta_{1 \mathrm{k}}=\beta_{2 \mathrm{k}}=\beta_{3 \mathrm{k}}=\ldots=\beta_{\mathrm{ik}}$ ). Persamaan yang digunakan adalah:

Tikem $_{i, t}=\alpha_{i}+\beta_{1} \mathrm{JP}_{\mathrm{i}, \mathrm{t}}+\beta_{2} \mathrm{IPM}_{\mathrm{i}, \mathrm{t}}+\beta_{3}$ PDRB $_{\mathrm{i}, \mathrm{t}}+\epsilon_{\mathrm{i}, \mathrm{t}}$

Struktur model ini mengasumsikan adanya perbedaan karakteristik tingkat kemiskinan (Tikem) di Provinsi Jawa Timur selama waktu observasi. Penggunaan kata fixed pada model FEM menunjukkan bahwa faktor penyebab heterogenitas setiap individu di asumsikan tetap sepanjang waktu observasi. Pengaruh yang tetap dapat dilihat dari penggunaan nilai yang sama (yaitu 1) sepanjang waktu. Nilai 1 ditempatkan pada individu tertentu dan nol untuk individu lainnya. Konsep ini disebut sebagai variabel dummy. Secara umum struktur model dalam bentuk Least Square Dummy Variabel (LSDV) adalah:

Tikem $_{\mathrm{i}, \mathrm{t}}=\alpha_{\mathrm{i}} \mathrm{D}_{1}+\alpha_{2} \mathrm{D}_{2}+\alpha_{3} \mathrm{D}_{3}+\alpha_{4} \mathrm{D}_{4}+\alpha_{5} \mathrm{D}_{5}+\beta_{1} \mathrm{JP}_{1 \mathrm{i}}+$ $\beta_{2}$ IPM $_{2 \mathrm{i}}+\beta_{3}$ PDRB $_{3 \mathrm{i}}+\mathrm{e}_{\mathrm{it}}$

\section{Metode Random Effect Model (REM)}

Pendekatan random effect mempertimbangkan setiap persamaan karakteristik individu. Penentuan $\alpha$ dan $\beta$ didasarkan pada asumsi bahwa intersep $\alpha$ terdistribusi random antar unit $\mu_{\mathrm{i}}$. dengan kata lain, slope memiliki nilai yang tetap tetapi, intercept bervariasi untuk setiap individu. Sehingga persamaan untuk model ini adalah:

Tikem $_{\text {it }}=\alpha_{1 i}+\beta_{\mathrm{JP}^{\mathrm{JP}}}+\beta_{\mathrm{IPM}} \mathrm{IPM}_{\text {it }}+\beta_{\mathrm{PDRB}} \mathrm{PDRB}_{\text {it }}+\mu_{\text {it }}$

Dari model ini dapat dilihat bahwa slope $\beta$ memiliki nilai tetap, tetapi intersep $\alpha_{1 \mathrm{i}}$ memiliki nilai yang bervariasi karena pengaruh random $\epsilon_{\mathrm{i}}$ terhadap intersep $\alpha_{1}\left(\alpha_{1 \mathrm{i}}=\alpha_{1}+\right.$ $\epsilon_{\mathfrak{i}}$ ) yang bernilai tetap. Dengan model ini diasumsikan bahwa pengaruh dari setiap individu sama.

\section{Pemilihan Model Data Panel}

\section{A.Uji Chow}

Uji Chow digunakan untuk memilih salah satu model terbaik pada regresi data panel, yaitu antara model efek tetap (fixed effect model) dengan Pooled Least Square Model (PLS).

\section{B.Uji Hausman}


Uji Hausman dilakukan untuk menentukan metode mana yang paling tepat antara Fixed Effect atau Random Effect.

\section{Uji Lagrance Multiplier (LM)}

Apabila dalam uji Hausman hasil model yang terbaik adalah Random Effect, maka dilanjutkan dengan uji Lagrance Multiplier (LM) yang dikembangkan oleh Breusch-Pagan.

\section{Hasil dan Pembahasan}

\section{Hasil}

Tabel 1. Perbandingan Estimasi Panel Data Model PLS, FEM dan REM.

Dependent lariable: IIR EN

\begin{tabular}{|c|c|c|c|c|c|c|}
\hline Vuriabel & Pls & Pont. & HEV & Prob. & REN & Prob. \\
\hline l & 19,59844 & 0.1000 & $(29,444]$ & 0.1000 & 90.76314 & 0.01001 \\
\hline IP & $8.10 \mathrm{e} \cdot 16$ & 0.0000 & $.6991 \cdot 1 j$ & 0.10001 & $.3 .14+E \cdot 16$ & 0.1111 \\
\hline IP II & $\cdot 1.036459$ & 0.0000 & .0 .100986 & 0.10010 & $\cdot 1.108521$ & 0.01001 \\
\hline PDRB & $\cdot 1.0100145$ & 0.0000 & $0.10011+0$ & $0.016 !$ & $8.198 \cdot 15$ & 0.0121 \\
\hline R-spuared & 0.9943 .66 & & 0.987676 & & $0.83179 !$ & \\
\hline
\end{tabular}

\section{Samber: Lampiran C,D,E}

Berdasarkan hasil estimasi panel data pada Tabel 1 dengan variabel terikat Tingkat Kemiskinan, Fixed Effect Model (FEM) menunjukkan hasil yang lebih baik dibandingkan Random Effect Model (REM) dan Pooled Least Square (PLS). Hal ini bisa dilihat dari nilai koefisien regresi dari masing-masing variabel bebasnya. Selain itu, nilai R-square $\left(\mathrm{R}^{2}\right)$ yang lebih baik terdapat pada Fixed Effect Model (FEM) dibandingkan model lainnya. Setelah dilakukan analisis untuk model tersebut, maka untuk memilih model yang terbaik antara Pooled Least Square (PLS),Fixed Effect Model (FEM) dan Random Effect Model REM) dapat dilakukan dengan uji Chow, Hausman dan Lagrange Multiplier (LM). Hasil estimasi mengenai model terbaik Fixed Effect Model akan dipaparkan dalam Tabel 4.9 berikut ini.

Tabel 2. Fixed Effect Model (FEM)

\begin{tabular}{|c|c|c|c|c|}
\hline Variable & Coefficient & Std, Entos & 1.Statistic & Prob. \\
\hline l & 129.4447 & 6.849599 & 18.89825 & 0.0000 \\
\hline IP & $\cdot 6.97 \mathrm{E} \cdot 0 \mathrm{j}$ & $1.11 E \cdot 0 j$ & .6 .307659 & 0.0000 \\
\hline $\mid P \|$ & .0 .100986 & 0.122332 & .5 .720820 & 0.0000 \\
\hline$P D R B$ & 0.000140 & $j .62 \mathrm{E} \cdot 05$ & 2.495022 & 0.0162 \\
\hline R-squared & 0.987696 & \multirow{3}{*}{\multicolumn{2}{|c|}{ 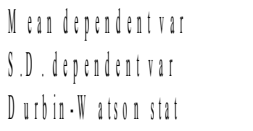 }} & 20,12467 \\
\hline Adjusted R-squased & 0.984330 & & & 4.151174 \\
\hline P.statistic & 313.9005 & & & 1.624996 \\
\hline Prob(P-statistic) & 0.000000 & & & \\
\hline
\end{tabular}

Sumber: Laupirane

Berdasarkan hasil estimasi panel data pada Tabel 4.9 dengan menggunakan pendekatan Fixed Effect Model (FEM) diperoleh hasil persamaan:

TIKEM $=129.4447-6.97 \mathrm{E}-05 * \mathrm{JP}-0.700986 * \mathrm{IPM}+$ $0.000140 * \mathrm{PDRB}+[\mathrm{CX}=\mathrm{F}]$

Persamaan regresi panel data di atas menjelaskan bahwa :

1.Nilai Konstanta tingkat kemiskinan di Provinsi Jawa Timur sebesar 129,4447 menunjukkan apabila variabel JP, IPM, dan
PDRB diasumsikan bernilai konstan maka diperkirakan tingkat kemiskinan pada 10 Kabupaten di Provinsi Jawa Timur sebesar 129,4447 persen.

2.Variabel Jumlah Penduduk berpengaruh negatif terhadap tingkat kemiskinan dengan koefisien regresi sebesar $-0,0000697$. Hal ini berarti apabila variabel jumlah penduduk meningkat 1 jiwa per tahun maka akan menurunkan tingkat kemiskinan pada 10 kabupaten di Provinsi Jawa Timur sebesar 0,0000697 persen.

3.Variabel IPM berpengaruh negatif terhadap tingkat kemiskinan dengan koefisien regresi sebesar -0,700986. Hal ini berarti apabila variabel IPM meningkat $1 \%$ per tahun maka akan menurunkan tingkat kemiskinan pada 10 kabupaten di Provinsi Jawa Timur sebesar -0,700986 persen.

4.Variabel PDRB berpengaruh positif terhadap tingkat kemiskinan dengan koefisien regresi sebesar 0,000140 yang berarti setiap penambahan 1 Milyar variabel PDRB maka akan meningkatkan tingkat kemiskinan pada 10 kabupaten di Provinsi Jawa Timur sebesar 0,000140 persen.

A. $\mathrm{Uji}^{2}$ (Koefisien Determinan)

Hasil estimasi panel data Tabel 4.9 menunjukkan nilai $\mathrm{R}^{2}$ sebesar 0,987676, artinya total variasi tingkat kemiskinan pada 10 kabupaten di provinsi Jawa Timur mampu dijelaskan oleh variabel-variabel independen JP, IPM, dan PDRB sebesar $98,76 \%$, sedangkan sisanya $1,24 \%$ dijelaskan variabel lain diluar model.

\section{B. Uji F Simultan}

Berdasarkan estimasi panel data Tabel 4.9, nilai probabilitas $\mathrm{F}_{\text {statistik }}$ sebesar 0,0000 lebih kecil dari nilai probabilitas kritis $(\alpha=5 \%)$, maka hipotesis nol $\left(\mathrm{H}_{0}\right)$ ditolak dan menerima hipotesis alternatif $\left(\mathrm{H}_{\mathrm{A}}\right)$, artinya semua variabel independen mampu menjelaskan variabel dependen atau secara bersamasama variabel independen JP, IPM, dan PDRB berpengaruh signifikan terhadap variabel dependen tingkat kemiskinan.

C. Uji t Parsial

Tabel 4.10 Uji t-statistik

\begin{tabular}{lcccc}
\hline Variable & Coefficient & Std. Error & t-Statistic & Prob. \\
\hline JP & $-6.97 \mathrm{E}-05$ & $1.11 \mathrm{E}-05$ & -6.307659 & 0.0000 \\
IPM & -0.700986 & 0.122532 & -5.720820 & 0.0000 \\
PDRB & 0.000140 & $5.62 \mathrm{E}-05$ & 2.495022 & 0.0162 \\
\hline
\end{tabular}

Sumber : Lampiran D

Berdasarkan uji t dapat disimpulkan bahwa :

1.Variabel JP memiliki nilai probabilitas $t_{\text {statistik }}$ lebih kecil daripada nilai kritis $\alpha=5 \%(0.0000<0,05)$. Dengan demikian hipotesis nol $\left(\mathrm{H}_{0}\right)$ ditolak dan menerima hipotesis alternatif $\left(\mathrm{H}_{\mathrm{A}}\right)$ yang berarti JP berpengaruh signifikan terhadap tingkat kemiskinan di Jawa Timur.

2.Variabel IPM memiliki nilai probabilitas $t_{\text {statistik }}$ lebih kecil daripada nilai kritis $\alpha=5 \%(0.0000<0,05)$. Dengan 
demikian hipotesis nol $\left(\mathrm{H}_{0}\right)$ ditolak dan menerima hipotesis alternatif $\left(\mathrm{H}_{\mathrm{A}}\right)$ yang berarti IPM berpengaruh signifikan terhadap tingkat kemiskinan di Jawa Timur.

3.Variabel PDRB memiliki nilai probabilitas $t_{\text {statistik }}$ lebih kecil daripada nilai kritis $\alpha=5 \%(0.0162<0,05)$. Dengan demikian hipotesis nol $\left(\mathrm{H}_{0}\right)$ ditolak dan menerima hipotesis alternatif $\left(\mathrm{H}_{\mathrm{A}}\right)$ berarti PDRB berpengaruh signifikan terhadap terhadap tingkat kemiskinan di Jawa Timur.

\section{Uji Asumsi Klasik}

Uji normalitas menunjukkan nilai probabilitas sebesar $0,078342>$ nilai probabilitas kritis $\alpha=5 \%(0,05)$, dapat ditarik kesimpulan bahwa model panel data tersebut terdistribusi normal karena nilai probabilitas JB statistik $_{\text {lebih }}$ besar dibanding nilai probabilitas kritis $\alpha=5 \%$.

Uji multikolinearitas menunjukkan bahwa hubungan antara masing-masing variabel bebas (JP, IPM, dan PDRB) semua berada di bawah $80 \%$ atau 0,8 (rule of thumb) sehingga dapat dinyatakan tidak terdapat masalah multikolinearitas dalam model penelitian.

Uji heteroskedastisitas menunjukkan hasil pengujian heterokedastisitas menggunakan uji Glejser, variabel dependen terhadap variabel independen secara parsial maka dapat dijelaskan sebagai berikut :

1.Variabel JP memiliki nilai probabilitas $t_{\text {statistik }}$ lebih besar daripada nilai kritis $\alpha=5 \%(0,7141>0,05)$. Dengan demikian $\mathrm{H}_{0}$ diterima yang berarti variabel JP tidak terjadi masalah heterokedastisitas.

2.Variabel IPM memiliki nilai probabilitas $\mathrm{t}_{\text {statistik }}$ lebih besar daripada nilai kritis $\alpha=5 \%(0,1343>0,05)$. Dengan demikian $\mathrm{H}_{0}$ diterima yang berarti variabel IPM tidak terjadi masalah heterokedastisitas

3.Variabel PDRB memiliki nilai probabilitas $t_{\text {statistik }}$ lebih besar daripada nilai kritis $\alpha=5 \%(0,6062>0,05)$. Dengan demikian $\mathrm{H}_{0}$ diterima yang berarti variabel PDRB tidak terjadi masalah heterokedastisitas.

Uji autokorelasi menunjukkan hasil penelitian menggunakan Durbin-Watson untuk menguji ada atau tidaknya masalah autokorelasi dalam model, pada Tabel 4.9 diperoleh dengan nilai Durbin-Watson sebesar 1,624996. Dengan nilai dL sebesar 1,4797 dan dU sebesar 1,6875, serta merujuk pada kriteria pengujian nilai Durbin-Watson, maka nilai tersebut masuk dalam kriteria kedua dengan kriteria $\mathrm{dL}<\mathrm{dw}<\mathrm{dU}$ atau $1,4797<1,6249<1,6875$.

\section{Pembahasan}

Pembahasan ini didasarkan pada hasil analisis yang telah dilakukan pada pembahasan sebelumnya. Pembahasan ini bertujuan untuk mengetahui pengaruh faktor JP, IPM, dan PDRB terhadap tingkat kemiskinan pada 10 kabupaten di Provinsi Jawa Timur. Dimana tingkat kemiskinan di Provinsi Jawa Timur ini adalah 10 kabupaten dengan tingkat kemiskinan tertinggi yang ada di Provinsi Jawa Timur. Selanjutnya akan diuraikan antara temuan empiris hasil penelitian yang telah diuji secara statistik dengan teori dan penelitian sebelumnya.

\section{Pengaruh JP terhadap Tingkat Kemiskinan pada 10 kabupaten di Provinsi Jawa Timur}

Berdasarkan hasil estimasi persamaan regresi data panel selama tahun 2010-2015 menunjukkan bahwa variabel JP mempunyai pengaruh negatif dan signifikan terhadap tingkat kemiskinan pada 10 kabupaten di Provinsi Jawa Timur. Variabel jumlah penduduk mempunyai nilai koefisien regresi $-0,0000697$ dan probabilitas t statistik 0,0000 memiliki arti jika variabel jumlah penduduk meningkat sebesar 1 jiwa per tahun, maka akan menurunkan tingkat kemiskinan sebesar 0,0000697 persen. Hasil penelitian yang menunjukkan jumlah penduduk berpengaruh negatif terhadap tingkat kemiskinan, hal ini tidak sesuai dengan hipotesis penelitian yang diajukan, sehingga hipotesis penelitian tidak dapat diterima. Namun hal ini serupa dengan hasil penelitian oleh Mahsunah (2013) yang menyatakan jumlah penduduk memiliki pengaruh negatif, hal tersebut menunjukkan adanya hubungan yang berbanding terbalik antara jumlah penduduk dengan kemiskinan, yaitu jika jumlah penduduk tinggi maka kemiskinan akan menurun.

Jumlah penduduk yang meningkat pada setiap 10 kabupaten tersebut tidak mempengaruhi tingginya tingkat kemiskinan yang ada, hal ini karena distribusi jumlah penduduk didominasi oleh usia-usia produktif. Usia produktif mendominasi sehingga banyak tersedia tenaga kerja yang dapat mendorong pembangunan ekonomi, sehingga jumlah penduduk yang lebih banyak adalah penduduk yang bekerja, terlibat secara aktif di pasar tenaga kerja baik dengan status bekerja, mencari pekerja atau sedang mempersiapkan usaha, hal ini dapat mendorong peningkatan kesempatan kerja karena usia produktif lebih mendominasi.

\section{Pengaruh IPM terhadap Tingkat Kemiskinan pada 10 kabupaten di Provinsi Jawa Timur}

Dari hasil estimasi menunjukkan bahwa variabel Indeks Pembangunan Manusia (IPM) mempunyai pengaruh negatif dan signifikan terhadap tingkat kemiskinan pada 10 kabupaten di Provinsi Jawa Timur. Nilai koefisien regresi $-0,700986$ dan probabilitas $t$ statistik 0,0000 memiliki arti setiap penambahan $1 \%$ variabel IPM akan menurunkan tingkat kemiskinan pada 10 kabupaten di Provinsi Jawa Timur sebesar 0,7 persen. Hal ini selaras dengan pernyataan Arsyad (1999:242) salah satu strategi pengentasan kemiskinan adalah dengan pembangunan sumber daya manusia, perbaikan akses terhadap konsumsi pelayanan sosial (pendidikan, kesehatan dan gizi) merupakan alat kebijakan penting dalam strategi pemerintah secara keseluruhan untuk mengurangi angka kemiskinan dan memperbaiki kesejahteraan penduduk untuk meningkatkan kualitas sumber daya manusia. IPM merupakan ukuran untuk pembangunan manusia secara relatif, apabila IPM meningkat berarti kesejahteraan masyarakat juga meningkat, dengan demikian kemiskinan menurun.

Terdapat tiga dimensi dasar IPM yaitu tingkat pendidikan atau pengetahuan, umur panjang dan hidup sehat dan standar hidup layak. Menurut Idris (2016:30) penerapan dari pendekatan teori human capital adalah pendidikan dan pelatihan sebagai faktor penting dalam pengembangan kualitas sumber daya manusia, selain menambah pengetahuan 
tetapi juga meningkatkan keterampilan bekerja sehingga mampu meningkatkan produktivitas kerja.

\section{Pengaruh PDRB terhadap Tingkat Kemiskinan pada 10 kabupaten di Provinsi Jawa Timur}

Dari hasil estimasi menunjukkan bahwa variabel PDRB berpengaruh positif dan signifikan terhadap tingkat kemiskinan pada 10 kabupaten di Provinsi Jawa Timur. Nilai koefisien regresi sebesar 0,000140 dan probabilitas t statistik 0,0162 yang berarti setiap penambahan 1 Milyar variabel PDRB maka akan meningkatkan tingkat kemiskinan sebesar 0,000140 . Hasil penelitian ini serupa dengan penelitian dari Purnamasari (2017) yang berjudul "Analisis Pengaruh Pertumbuhan Ekonomi dan Ketimpangan Pendapatan Terhadap Kemiskinan di Provinsi Jawa Timur tahun 20102014" yang menyatakan bahwa variabel pertumbuhan ekonomi mempunyai pengaruh positif dan signifikan terhadap kemiskinan di Jawa Timur pada tahun 2010-2014.

Pertumbuhan ekonomi tanpa disertai dengan penambahan kesempatan kerja akan mengakibatkan ketimpangan dalam pembagian dari penambahan pendapatan, yang selanjutnya akan menciptakan suatu kondisis pertumbuhan ekonomi dengan peningkatan kemiskinan (Tambunan, 2003:40-41). Selanjutnya pembangunan ekonomi tidak hanya diukur berdasarkan peningkatan PDRB secara keseluruhan, tetapi harus memperhatikan sejauh mana distribusi pendapatan telah menyebar ke lapisan masyarakat serta siapa saja yang telah menikmati hasil-hasilnya. Jadi dalam hal ini memang PDRB meningkat namun peningkatan ini didominasi dari kelas menengah keatas, sehingga orang yang kaya akan semakin kaya, tetapi kemiskinan juga semakin bertambah. Ini terjadi karena tidak diimbangi dengan pemerataan distribusi pendapatan serta pemerataan hasil-hasil ekonomi keseluruh lapisan golongan masyarakat, sehingga menyebabkan ketimpangan pendapatan.

\section{Simpulan}

Berdasarkan hasil analisa dan pembahasan yang telah dilakukan dapat diambil kesimpulan sebagai berikut: 1) Jumlah Penduduk (JP) memiliki pengaruh negatif dan signifikan terhadap tingkat kemiskinan di setiap wilayah analisis Provinsi Jawa Timur tahun 2010 - 2015. Hal ini berarti bahwa Jumlah Penduduk meningkat akan menurunkan tingkat kemiskinan; 2) indeks Pembangunan Manusia (IPM) memiliki pengaruh negatif dan signifikan terhadap tingkat kemiskinan di setiap wilayah analisis Provinsi Jawa Timur tahun 2010 - 2015. Hal ini berarti bahwa semakin tinggi Indeks Pembangunan Manusia (IPM) maka akan menurunkan tingkat kemiskinan; 3) Produk Domestik Regional Bruto (PDRB) memiliki pengaruh positif dan signifikan terhadap tingkat kemiskinan di setiap wilayah analisis Provinsi Jawa Timur tahun $2010-2015$.

\section{Referensi}

Arsyad, Lincolin. 1999. Ekonomi Pembangunan. Yogyakarta: STIE YKPN.

Badan Pusat Statistik Provinsi Jawa Timur. 2016. Jawa Timur dalam Angka. Badan Pusat Statistik Provinsi Jawa Timur.

Ekananda, Mahyus. 2015. Ekonometrika Dasar. Jakarta: Mitra Wacana Media.

Ekananda, Mahyus. 2016. Ekonometrika Data Panel. Jakarta: Mitra Wacana Media.

Herjanto, Eddy. 2007. Manajemen Operasi edisi ketiga. Jakarta : Grasindo.

Idris, Amiruddin. 2016. Pengantar Ekonomi Sumber Daya Manusia. Yogyakarta : Deepublish.

Mahsunah, Durrotul. 2013. Analisis Pengaruh Jumlah Penduduk, Pendidikan, dan Pengangguran Terhadap Kemiskinan Di Jawa Timur. Jurnal. Fakultas Ekonomi Universitas Negeri Surabaya

Nasir Muh M, Saichudin dan Maulizar. 2008. Analisis faktor-faktor yang mempengaruhi Kemiskinan Rumah Tangga di Kabupaten Purworejo. Jurnal eksekutif. Vol 5. No.4, agustus 2008. Lipi : Jakarta

Nurdiansyah, Sudrajat. 2016. Analisis faktor-faktor yang mempengaruhi kemiskinan di karisidenan Besuki dan Lumajang tahun 2008-2013. Skripsi. Fakultas Ekonomi Universitas Jember.

Purnamasari, Oktina. 2017. Analsisi Pengaruh Pertumbuhan Ekonomi dan Ketimpangan Pendapatan Terhadap Kemiskinan di Provinsi Jawa Timur 2010-2014. Jurnal. Fakultas Ekonomi Universitas Islam Negeri Sunan Kalijaga Yogyakarta.

Simatupang, Pantjar dan Saktyanu. 2003. Produk Domestik Bruto, Harga, dan Kemiskinan. Media Ekonomi dan Keuangan Indonesia, hal 191324, vol. 51, no.3.

Stokes, Jane. 2006. Panduan untuk Melaksanakan Penelitian dalam Kajian Media dan Budaya. Yogyakarta : Bentang Pustaka

Tambunan, Tulus H. 2003. Perekonomian Indonesia : Teori dan Temuan Empiris. Jakarta: Ghalia Indonesia. 